\title{
Diabetes Treatment Guidelines and Nurses' Adherence to Them: A Case of the UK and Kuwait
}

\section{Alshammari $\mathbf{M}^{1 *}$, Windle $\mathrm{R}^{2}$ Bowskill $\mathrm{D}^{2}$ and Adams $\mathrm{G}^{2}$ \\ ${ }^{1}$ College of Nursing, Public Authority for Applied Education and Training, Kuwait \\ ${ }^{2}$ Faculty of Medicine \& Health Sciences, University of Nottingham, UK}

*Corresponding author: Muna Alshammari, Public Authority for Applied Education and Training, College of Nursing, Kuwait, Tel: +965 223159621; Email: alshammari_pinky@msn. com

\section{Research Article \\ Volume 4 Issue 1}

Received Date: January 02, 2020

Published Date: February 07, 2020

DOI: $10.23880 /$ nhij-16000214

\section{Abstract}

Background: The management of diabetes requires new models of care, of which nurses have been identified as key players. It is observed that adequate preparation and proper guidance of nurses with knowledge and skills in diabetes care is important for their care role. It is also essential that nurses use evidence to inform their care role towards diabetes patients, which can be achieved through using up-to-date guidelines on diabetes care and treatment. However, it is not clear how guidelines inform the nursing diabetes care role and to what extent nurses use the guidelines in diabetes care. This article reports findings from a review of guidelines on the role of nurses in diabetes care, and how nurses adopt these guidelines in patient care.

Methods: The study adopted a case study approach, in which two cases (the United Kingdom and Kuwait) were involved. We reviewed local, national and international guidelines that inform the role of nurses in diabetes care. Following analysis of the findings from the guidelines, we compared the prescribed roles of nurses in diabetes care as informed by the guidelines against those performed in practice.

Findings: In total, eight guidelines were reviewed, four from each case. The findings revealed a number of roles that guide diabetes nursing care including: patient assessment, patient education, providing patient-centred care, promoting self-care, prescription role, team work, and adapting diabetes care to local needs. The findings showed that nurses utilise the guidelines to guide their work of nursing diabetes patients and while doing this, they take into consideration the individual needs of their patients.

Conclusions: The study concluded that guidelines on diabetes care are essential in the provision of patient focused care, hence the need for their adoption in all healthcare settings. It is important that the guidelines provide specific roles for the different practitioners, and be flexible to adequately address the needs of the patients. Further research is essential to assess the application of international, national, and local guidelines and how their application influence diabetes care delivery.

Keywords: Diabetes; Guidelines; Nurses; UK; Kuwait 


\section{Introduction}

The American Diabetes Association (ADA) [1] has reported an increasing trend in diabetes. The International Diabetes Federation (IDF) projects an increase in the newly diagnosed diabetes cases of 14.6 percent to 16.9 percent by 2030 [2], while this number is predicted to double by the year 2034 [3].

According to the International Diabetes Federation [IDF], diabetes is defined as 'a state of high blood glucose associated with early death' [2]. The causes of diabetes have been identified to include a lack of insulin production or the lack of effectiveness of the insulin produced by the pancreas (World Health Organisation (WHO)) [4]. Diabetes is reportedly more prevalent among men due to biological susceptibility and individuals within the ages of 40-59 years $[5,6]$. According to the US Center for Disease Control and Prevention (CDCP), three main types of diabetes exist and they include Type 1, Type 2, and gestational diabetes [7]. Of these types, Type 2 diabetes is the most prevalent and comprises about $90 \%$ of all cases [2].

Type 2 Diabetes (T2D) is defined as chronic hyperglycaemia caused by decreased insulin production, impaired insulin function or, mutually, in the absence of autoimmune damage of the pancreatic beta cell [8]. In T2D disorder, there is insulin insensitivity that results in failure of the pancreas to secrete insulin [7]. Type 2 Diabetes tends to show no early symptoms, which makes early diagnosis difficult [9], yet showing up late may make patients to present with diabetes complications [2]. Hence it is important to pay attention to T2D in order to prevent its complications which may lead to poor health outcomes. Consequently, the management of T2D is seemingly an on-going challenge in the healthcare sector.

Research shows that diabetes is on the rise in recentyears in the UK [9] and Kuwait [10]. In Europe, the UK is one of the highest burdened countries with diabetes, while Kuwait was classified as one of the top ten countries worldwide with a high prevalence of diabetes [8]. The high burden of diabetes disease in the two countries indicates a need for intensifying treatment, care and preventive measures to address the challenge. It has been suggested that empowering nurses who attend to diabetes patients can greatly contribute to the general management of diabetes and to improve patient' outcomes [11].

\section{The Role of Nurses in Diabetes Care}

The management of diabetes requires new models of care. It is reported that adequate preparation and proper guidance of nurses with knowledge and skills in diabetes care is essential for their care role [12]. However, the role of nurses has not been fully understood, in terms of their support to diabetes patients. Nurses also work with other colleagues in diabetes care, and this creates the need for their role to be specified as part of collaborative care [13].

Increasingly, healthcare systems are adopting nurseled models that appear to be patient centred compared with the traditional physician-led approach that reflects a medically - oriented model of care. It has been reported that when nurses are effectively trained and well guided, they can adequately undertake some roles in the management of specific diseases [11]. Currently, trends in healthcare suggest a task shift where nurses increasingly engage in roles previously performed by physicians [14]. Nurses have also been reported to demonstrate diverse and complex consultant roles in providing high standards of patientcentred care [15].

The nursing based model of care has been described as patient-centred, and believed to result in favourable patient outcomes. In a comparative study by Vrijhoef, et al. [16] that sought to establish the impact of care provided to T2D by nurses as opposed to that by doctors it was established that clinical outcomes for both nurses and doctors were similar while other parameters such as self-care behaviour, patient satisfaction, and glycaemic control had improved using the nurse-led model. In a similar study that compared a nurse led hypertension clinic with conventional community care among T2D patients, Denver, et al. [17] found that nurse led care had better improvements in systolic blood pressure within a six month period of control in a nurse-led clinic. These data thus highlight the need to engage nurses in the management of T2D.

\section{Guidelines for Diabetes Treatment}

The absence of a well-defined role for nurses has caused a lack of support, alongside underutilisation of their role [18]. It is essential that nurses use evidence to inform their care role towards diabetes patients, which can be achieved through using up-to-date guidelines on diabetes care and treatment. In some healthcare systems, nurses seem to experience confusion related to their expected role(s) regarding diabetes care, in terms of what to perform based on specific guidelines and what not to perform (i.e. what is beyond their scope of practice) [19].

Guidelines used for diabetes care should be evidence based and theory driven [10]. Research indicates that when guidelines that are evidence based are used in patient care, there are better patient outcomes [20]. Findings from a study by Houweling, et al. [21], indicated that nurses working in diabetes care, when using national guidelines (Dutch College 
of General Practitioners and Dutch Diabetes Federation), were able to provide effective T2D care for patients comparable to that provided by doctors.

Despite the importance attributed to the use of guidelines in diabetes care, some nurses find it difficult to follow the guidelines during daily work [19]. It is not clear therefore to what extent nurses use guidelines in diabetes care. The lack of evidence regarding what guidelines stipulate to be the roles of nurses in diabetes care and what actually is undertaken creates a need for research in this area. This evidence will be essential to estimate the quality of nursing practice in diabetes care.

\section{Study Aim}

This article reports findings from a review of guidelines on diabetes care in UK and Kuwait, and how nurses adopt these guidelines in patient care. The article is part of a larger study that investigated the role of nurses in diabetes care and its impact on patients' perceived quality of nursing care, undertaken by a PhD student from Kuwait, at a UK University, with expertise in chronic diseases and qualitative research. The findings of this research will provide evidence that could be used in developing a new system of diabetes care.

\section{Methodology}

This was a case study on the roles of nurses in diabetes care, involving two cases (United Kingdom and Kuwait), with two sites from each case. We reviewed local, national and international guidelines that inform the role of nurses in diabetes care, in the UK and Kuwait. Following analysis of the findings from the guidelines, we compared the prescribed roles of nurses in diabetes care as informed by the guidelines against those performed in practice as reported in another article, which explored the performed roles of nurses in diabetes care [22].

\section{Selection of Guidelines}

To gain access to the relevant diabetes care guidelines, we approached the healthcare staff who worked with various institutions and had authority over the guidelines. Nurses in charge, the head nurse in Kuwait and the matron in the UK provided the researcher with a list of guidelines followed in each clinic including hard copies of the national and local guidelines. They identified the international, national and local guidelines used in their respective clinics. Through internet searches, the website for each organisation was located and the named guidelines were found. In both the UK and Kuwait, the national guidelines and the local guidelines were collected from nurses in-charge.

\section{Types of Guidelines Accessed}

\section{The UK Case Study}

Four (4) guidelines were reviewed in the UK case, which included three national guidelines and one local guideline. The national guidelines were; the Competency Framework for Diabetes Nursing (NCF), the Royal College of Nursing (RCN) Guidelines for Diabetes [9], and the National Institute for Health and Care Excellence guidelines (NICE).

\begin{tabular}{|c|l|l|c|c|c|}
\hline Originators & Year & Type & Authors & Target population & $\begin{array}{c}\text { No. of } \\
\text { pages }\end{array}$ \\
\hline $\begin{array}{c}\text { Competency } \\
\text { Framework for } \\
\text { Diabetes Nursing } \\
\text { (NCF) }\end{array}$ & 2005 & National & $\begin{array}{c}\text { Professional bodies Representing nurses } \\
\text { who work in diabetes care }\end{array}$ & $\begin{array}{c}\text { Nursing staff with different } \\
\text { levels of knowledge, } \\
\text { experience and education } \\
\text { providing diabetes care }\end{array}$ & 36 \\
\hline $\begin{array}{c}\text { National Institute } \\
\text { for Health and Care } \\
\text { Excellence (NICE) }\end{array}$ & 2015 & National & $\begin{array}{c}\text { Professional bodies Representing } \\
\text { general Healthcare professional } \\
\text { including nurses who work in diabetes } \\
\text { care }\end{array}$ & $\begin{array}{c}\text { Health care professionals } \\
\text { providing care to people with } \\
\text { diabetes }\end{array}$ & 57 \\
\hline $\begin{array}{c}\text { Royal college of } \\
\text { nursing Guidelines } \\
\text { for Diabetes (RCN) }\end{array}$ & 2006 & National & $\begin{array}{c}\text { RCN nurses, Paediatric and Adolescent } \\
\text { Diabetes Group, other disciplines and } \\
\text { people with diabetes }\end{array}$ & $\begin{array}{c}\text { Nursing staff Providing } \\
\text { diabetes care }\end{array}$ & 16 \\
\hline $\begin{array}{c}\text { The Nottingham } \\
\text { Diabetes Service } \\
\text { Advisory Group } \\
\text { (NDSAG) }\end{array}$ & 2006 & Local & $\begin{array}{c}\text { Professional Bodies including } \\
\text { physicians, dieticians, and nurses } \\
\text { representing general healthcare } \\
\text { professionals including nurses who } \\
\text { work in diabetes care in Nottingham }\end{array}$ & $\begin{array}{c}\text { Nursing staff providing } \\
\text { diabetes care }\end{array}$ & 39 \\
\hline
\end{tabular}

Table 1: Guidelines Adopted in the UK Case Study. 
The NCF and RCN guidelines present general roles for nurses in the UK, while NICE presents recommendations for general healthcare providers working in diabetes care in the UK. The local guideline reviewed is established by the Nottingham Diabetes Service Advisory Group (NDSAG), a multidisciplinary group of healthcare professionals, including nurses specifically designed for the county of Nottinghamshire. The NDSAG guidelines were derived from a number of sources including international guidelines such as those from the American Diabetes Association (ADA), the International Diabetes Federation (IDF), as well as UK-centric sources such as NICE and the Diabetes UK website. Table 1 below presents the main characteristics of the guidelines that were reviewed in the UK case.

\section{Kuwait Case Study}

Three international guidelines and one local guideline were reviewed in the Kuwait case. The international guidelines included American Diabetes Association (ADA), the International Diabetes Federation (IDF), and the Canadian Diabetes Association (CDA). These international guidelines present general roles for various healthcare team members working in diabetes care. For instance, the ADA guidelines specify the roles of physicians, diabetes educators, registered dieticians, and other specialised staff in other areas $[3,23]$. The local guideline was set up by physicians and laid down the nurse's role plus those of doctors in diabetes care. (Table 2) below describes the guidelines reviewed in the Kuwait case.

\begin{tabular}{|c|c|c|c|c|c|}
\hline Originators & Year & Type & Authors & Target population & $\begin{array}{l}\text { No. of } \\
\text { pages }\end{array}$ \\
\hline $\begin{array}{c}\text { American Diabetes } \\
\text { Association (ADA) }\end{array}$ & 2013 & International & $\begin{array}{c}\text { Professional bodies } \\
\text { Representing health care } \\
\text { professionals including nurses }\end{array}$ & $\begin{array}{c}\text { Health care professionals } \\
\text { providing care to people } \\
\text { with diabetes }\end{array}$ & 41 \\
\hline $\begin{array}{l}\text { International Diabetes } \\
\text { Federation (IDF) }\end{array}$ & 2015 & International & $\begin{array}{c}\text { Professional bodies } \\
\text { Representing health care } \\
\text { professionals including nurses }\end{array}$ & & 132 \\
\hline $\begin{array}{l}\text { Canadian Diabetes } \\
\text { Associ ation (CDA) }\end{array}$ & 2013 & International & $\begin{array}{c}\text { Professional bodies } \\
\text { Representing health care } \\
\text { professionals including nurses }\end{array}$ & $\begin{array}{c}\text { Health care professionals } \\
\text { providing care to people } \\
\text { with diabetes } \\
\end{array}$ & 227 \\
\hline Doctors' guidelines & 2003 & Local & $\begin{array}{c}\text { Doctors and nurses working } \\
\text { in endocrinology and diabetes } \\
\text { care }\end{array}$ & $\begin{array}{l}\text { For nurses providing } \\
\text { diabetes care }\end{array}$ & 10 \\
\hline
\end{tabular}

Table 2: Guidelines Adopted in Kuwait.

\section{Data Extraction}

Relevant data from reviewed documents were extracted thematically. Key areas of interest included all described roles that nurses are expected to perform, either individually, or collaboratively with other healthcare providers. Key themes were identified and accordingly grouped as they emerged from the individual guidelines. All documents contributed to more than one theme.

\section{Data Analysis}

Thematic analysis was used to analyse the data extracted from the guidelines. This involved an aggregation of the extracted data into codes, categories and finally themes, presented as analytical words/statements. The thematic analysis approach [24] helped the researchers to constantly compare emerging themes. Comparison of the nurse's role as prescribed in the guidelines with those actually performed in practice [22] was done. Data analysis followed the standard case study approach, where individual cases were first analysed separately, followed by a cross-case analysis, in which findings from both cases were compared and merged where appropriate. Findings were presented as themes with representative extracts to support the researcher's interpretations.

\section{Findings}

This section reports the synthesised findings from reviewed guidelines on diabetes care, and a comparison of the findings from the guidelines with the reported roles of nurses in diabetes care, as reported in another article [22].

\section{Guideline Review Findings Pertaining to the Role of Nurses in Diabetes Care}

The primary aim of the guideline review was to investigate all the identified guidelines, which inform the role of nurses in diabetes care. Some of the guidelines were specifically designed for nurses, while others were designed for both nurses and other healthcare professionals who were 
providing diabetes care, such as doctors and dieticians. The reviewed documents exposed various practices/roles that are required of the diabetes nurse. Although some of the roles were crosscutting across disciplines, the roles were comparably similar with those expressed by the diabetes nurses [22]. The roles of nurses in diabetes care as reported in the guidelines include a wide range of duties as shown in the following sections.

\section{Patient Assessment/Screening}

The guidelines indicated patient assessment/screening as one of the roles of nurses in diabetes care. Nurses are expected to participate in the screening of diabetes patients in order to facilitate early detection and management of diabetes cases. In addition, nurses are expected to provide ongoing monitoring of diabetes patients once diagnosed, through monitoring of various parameters such as blood or urine glucose levels, administered drugs, and the general progress of the patients.

Screening, prevention and early detection of type 2 diabetes, promoting self-care, mental health, nutrition, urine monitoring, blood glucose monitoring, oral therapies and injectable therapies, hypoglycaemia, hyperglycaemia, intercurrent illness, managing diabetes in the hospital, pregnancy, hypertension and coronary heart disease, neuropathy, nephropathy, retinopathy ... (NCF-NUH p.9)

...managing cardiovascular risk, managing blood lipids, antithrombolytic therapy, managing blood pressure, identifying and managing long-term complications, and care for people in the hospital. (NICE-NUH p.7)

...detecting and managing complications. (RCN-NUH p.5)

The guidelines emphasise that screening programmes should be incorporated within each individual patient's care pathway, so as to be more patient-centred.

Participate in ... the identification, treatment and prevention and on the impact that hypoglycaemia or hyperglycaemia has on the individual; identify and teach appropriate strategies for prevention of hypoglycaemia during and after exercise. (NCFNUH p.18)

\section{Patient Education}

The role of nurses in health education and health promotion was clearly stated in the guidelines. The guidelines emphasised the requirement of nurses' participation in arranging patient educational programmes which should be structured to meet the patients' needs. Guidelines from both countries provided extensive guidance on the areas of health education, with details on contextual specifications that should be considered for diabetes care.
Offer structured education to adults with type 2 diabetes and/ or their family members or carers (as appropriate) ... (NICENUH p.7)

Meet the local cultural, linguistic, and cognitive and literacy needs; programmes are integrated with the care pathway. (NCF-NUH p.19)

The international guidelines required nurses to arrange and provide the patient with structured, individualised and/or a group-based education addressing the patient's condition and needs. In this regard, nurses were expected to consider patients' cultural backgrounds and beliefs, together with other issues related to their psychological and disability needs. Nurses were also expected to use techniques to facilitate education according to patients' learning styles, particularly those patients who have specific needs and requirements:

Structured patient education ... group or individual education ...ensure that education is accessible to all people with diabetes considering; culture, ethnicity, psychological, and disability issues, delivering education in the community or at diabetes local centres and in different languages ... use techniques of active learning adopted to personal choices and learning styles ... use modern communication technologies to advance the methods of delivery of diabetes education. (IDF-MoH p.101)

The reviewed guidelines stated that nurses should also provide education to the patient's caregivers, as they might help in facilitating a patient's health education. Furthermore, nurses were expected to provide education to other healthcare team members, such as nurses from other units and hospitals.

Participate in educating the people with diabetes, other HCPS and carers of people with diabetes. (NCF- NUH p.31)

Educate ward nurses and train nurses coming from other hospitals about the methods of health education and follow up with patients and all about diabetes. (Doctors' guidelines$\mathrm{MoH})$

Lifestyle modification was one of the practices stated in the guidelines, in which nurses should be involved, by providing suggestions about dietary advice according to patients' specific situations, taking into account their needs, their cultural beliefs, and their willingness to follow a plan of care. Education provided to patients and other healthcare team members should cover healthy lifestyles, which should lead to controlled glucose levels, blood pressure, and lipid profiles. Nurses were expected to participate actively in providing education to cover these significant issues in diabetes care, which could minimise the negative impact of diabetes and other complications:

Provide dietary advice in a form that is sensitive to the person's 
needs, culture and beliefs, being sensitive to their willingness to change ...... .

Integrated dietary advice with diabetes management plan, including other aspects of lifestyle modification, such as increasing physical activity. (NICE-NUH p.4)

Increase activity levels within the patient capability and reduce sedentary behaviour at home and increasing walking .... (NDSAG-NUHp.16).

Advise people with type 2 diabetes that healthful eating will improve overall health; attain individualised glycaemic, BP, and lipid goals; achieve and maintain body weight goals; physical activity considerations .... (ADA MoH S73)

\section{Providing Patient-Centred Care}

The provision of patient-centred care emerged as an important nurses' role in diabetes care.

To provide high-quality, person-centred care and services ... . To ensure consistently good quality care for people with diabetes. (NCF-NUH p.3)

Patient-centred care approaches highlighted in the documents included providing patient follow-up care and keeping the patient informed about their own plan of care. The guidelines oblige nurses to identify uncompliant persons and to plan follow-up sessions with them:

Identify those people who are not attending hospital or clinic appointments and follow-up non-attendance. (RCN-NUH p.11)

Patients need regular follow-up and recall for review of their conditions, and ongoing education and support. (RCN-NUH p.2)

It was noted that nurses involved in diabetes patient care were expected to provide the patients with support by creating and maintaining a good relationship with them. This approach encouraged patients' empowerment to selfmanage their diabetes. To achieve better patient outcomes, nurses need to share the plan of care with the patient so that they can agree and accept it. By involving the patient, the nurse creates a collaborative work environment, which encourages patient involvement in the plan of care. Patient empowerment allows patients to ask questions, so that they can express their needs and concerns:

...encourage collaborative relationship, by actively involving the person with diabetes in consultation, and create opportunity for them to ask questions and express concerns beside addressing patients main issues; provide all aspects of diabetes control and complications to all people with type 2 diabetes; agree a care plan with each person with diabetes, review care plan as needed and modify it according to changes in wishes and circumstances; provide telephone contact between clinic visits. (IDF-MoH p.15).
A patient's psychological support was considered a key factor in providing patient-centred care in two of the guidelines (NCF and RCN). These guidelines considered a holistic approach as the most appropriate approach to meet most patients' needs, including psychological ones. In these instances, the nurse should be aware of any changes in the patient's mental health status and should confirm that the patient, who is taking medications, is aware of how to take the medications and be aware about the effect of these medications on their diabetes. In case the patient is prone to changes in their normal mental health, the nurse should report this and recognise if the patient needs referral to a specialist:

Have an awareness of how mental health issues, such as depression and anxiety, affect people with diabetes; Report any potential changes in the person's normal mental health ...; Ensure people with diabetes and mental health problems understand how to take medication, recognise common sideeffects and how to report them; Demonstrate knowledge of the psychological impact of diabetes and facilitate referral to psychological support or mental health services, as required; Refer or ensure an appropriate mental health practitioner is involved in the person's care if they are demonstrating mental health difficulties. (NCF-NUH p.11)

Identify people with complex emotional needs and offer referral to a psychologist. (RCN-NUH p.10).

\section{Promoting Self-Care (Patient Empowerment)}

Patient-centred care also entailed the need for patient empowerment to facilitate self-care. Nurses are required to facilitate patient empowerment, by ensuring that patients are involved in planning and sharing plans of their treatment. Nurses are also responsible for raising patients' awareness about the national services from which patients can receive care. Patient self-management of diabetes is expected to enhance and support the patient's needs in a holistic manner. Be partners in decision-making ..., to give them more personal control over their day-to-day diabetic management, and to ensure the best possible quality of life. (RCN-NUH p.7) To help people with diabetes to be confident to self-manage their condition and to be as independent as possible. (NCFNUH p.5)

Discuss the purpose of self-monitoring and how to interpret and act on the results. (NICE-NUH p.8)

Nurses were recommended to encourage patients with diabetes and their family caregivers to decide about their care plans and the options of care which would impact on their quality of life. In addition, guidelines recommended nurses to support patients to develop self-management strategies so that they become knowledgeable about their own care and about other conditions that result from uncontrolled 
diabetes.

The ability of the person with diabetes to self-care and work with them or their carer to optimise self-care skills. (NDSAGNUH p.34)

...encourage self-management of diabetes (food choice, selfmonitoring, insulin dose adjustment where appropriate); ensure awareness of special risks to people with diabetes during hospital procedures, including risks; provide guidelines driven care to ensure detection and immediate control of hyperglycemia for anyone with a presumed acute coronary event or stroke; Daily ward rounds to follow up with diabetes patients. (ADA-MoH S84)

A patient's ability to self-manage their diabetes should be assessed by a nurse, as some patients are not able to achieve self-care. Once the nurse has established preliminary information about the patient's ability to cope with selfmanagement, the nurse should educate the patient about how to self-manage their own diabetes care. These skills were identified including enhancement of the patient's overall knowledge and experience needed in managing and controlling diabetes:

The ability of the person with diabetes to self-care and work with them or their carer to optimise self-care skills; ... encourage informed decision making about living with diabetes and managing life events; ... setting realistic goals and in the achievement of those goals. (NDSAG-NUH p.32)

... provide tailored, structured education and support to optimise self-care skills and promote informed decisionmaking about lifestyle choices; ...make informed choices about controlling and monitoring their diabetes ... ; risk reduction; monitoring control; and complications; Develop and ensure delivery of educational materials; work with the person with diabetes to facilitate lifestyle adjustment in response to changes in their diabetes or circumstances. (NCF-NUH p.10)

\section{Prescribed Role}

Guidelines especially those from the UK clearly elaborated on the prescription role of nurses in diabetes care. Nurses had a significant influence on prescribing and adjusting medications according to the nurse's scope of practice, under both legislation and local guidelines:

... prescribe medications, as required, within own competencies and scope of practice according to legislation and local guidelines ....

Adjust insulin treatment according to age, diagnosis and individual circumstances as appropriate, following local policies or individual clinical management plans. (NDSAGNUH p.31).

Although some guidelines still lacked concrete guidance on the role of prescription, there was hope being anticipated in the near future. The RCN guidelines suggested a future plan in which: Many more nurses will be able to prescribe medications within the framework of supplementary prescribing. (RCN- NUH p.2).

In Kuwait however, guidelines were not explicit regarding the prescription role of nurse in diabetes care. According to the $\mathrm{MoH}$ Kuwait, nurses are not allowed to prescribe, while the international guidelines mentioned nurses' involvement in providing medication advice to most diabetes patients, including patients taking oral therapies or injectable therapies such as insulin. Nurses are expected to: ... provide guidelines for adjusting medications and insulin (IDF-MoH) and to help them to identify appropriate: sites for insulin injection and self-injection and rotation of sites of injection (ADA-MoH S78).

\section{Multidisciplinary/Team Work}

An important approach identified in the diabetes care guidelines was teamwork. This model included the provision of patient care that would ensure an appropriate quality of life through collaborative work; firstly, between nurses and secondly between nurses and other healthcare professionals. Nurses are required to demonstrate knowledge about a teamwork approach. The teamwork model was highlighted in the majority of the guidelines, which included nurses interacting with other team members at the clinic to accomplish their duties and tasks:

Communicate with other healthcare professionals; perform other tasks advised by the direct consultant. (Doctors' guidelines-MoH)

Use an appropriately trained multidisciplinary team to provide education to groups of people with diabetes, or individually if group work is considered unsuitable. (IDF-MoH p.15)

According to the standards in the guidelines, a teamwork approach would minimise and control long-term diabetes complications, as teamwork adds quality to the guidelinedriven approach. In order to confirm the provision of effective patient care, collaboration between nurses in different specialisations is important:

Teamwork is vital - there should be good liaison between the ward nurse, practice nurse, district nurse or diabetes specialist nurse. This will ensure more effective care and that the advice offered to patients is consistent. (RCN-NUH p.11)

Optimise quality of life for people with diabetes and to reduce their risk oflong-term diabetic complications. A team approach is likely to provide the best outcomes. (RCN-NUH p.7).

Patients in need of foot care ... a specialist foot-care team will include staff with educational skills (usually podiatrists or trained nurses). (ADA-MoH S58).

The use of inter-professional teams which could include... diabetes educator, dietician, nurse, pharmacist, and other 
specialists (CDA-MoH p.35).

The above suggestions provide useful guidance for the organisation of care in diabetes management.

\section{Adapting Diabetes Care to Local Needs}

Guidelines suggested that nurses should follow some local recommendations generated at local levels, such as local policies and individual clinical management plans that consider patients' conditions and circumstances.

Adjust insulin treatment according to age, diagnosis and individual circumstances as appropriate, following local policies or individual clinical management plans (NDSAGNUH p.31).

Some guidelines were more extensive by providing context specific information such as the settings where diabetes care services should be extended. For example: Prison and young offender units, residential and nursing homes, and end of-life care ... (NCF-NUH p.32), where diabetes care is needed.

Similarly, some guidelines provided more context specific information, such as on populations that require diabetes care in terms of age, geographical location and gender:

Preventing type 2 diabetes, identifying people with diabetes, empowering people with diabetes, clinical care of adults with diabetes, clinical care of children and young people, diabetes emergencies, caring for people in the hospital, diabetes and pregnancy, and detecting and managing complications (RCNNUH p.5).

\section{Nurses' Adherence to Diabetes Treatment/Care Guideline}

The reviewed guidelines demonstrated a wide range of roles that nurses working in diabetes care should undertake. All nurses that were interviewed reported being fully aware of the existing guidelines, which were used as a source of information and informed them of the minimum level of care to be provided to diabetes patients. Although generally nurses in both case studies were aware and appreciated how both international and local guidelines inform and give direction to their work, some found the guidelines restrictive. In Kuwait, nurses considered local guidelines to be more helpful since they were more specific and focused compared with the international guidelines that were considered general and broad.

In this section, we compare the prescribed diabetes care roles with those performed by nurses in their practice. We have not presented full assessment of the roles undertaken by diabetes nurses as these were presented in another article entitled: Nurses' perspectives about their role in diabetes care: a case study analysis [22], which is currently under review. Hence, this section mainly provides a synthesised assessment of how nurses did/did not performed the roles prescribed in the diabetes care guidelines.

\section{Patient Assessment/Screening}

Guidelines indicated assessment/screening of patients as one of the roles nurses should undertake in diabetes care, in order to facilitate early detection and management of the patients. In addition, nurses are expected to provide ongoing monitoring of diabetes patients once diagnosed, through monitoring of various parameters such as blood or urine glucose levels, administered drugs, and the general progress of the patients. According to nurses' perspectives, it was not clear whether/how they participate in the assessment/ screening of patients for diabetes. However, nurses reported actively taking part in the monitoring of patients who have been diagnosed and are on treatment.

\section{Patient Education}

The role of nurses in health education and health promotion was clearly stated in the guidelines. The guidelines emphasised the requirement of nurses' participation in arranging patient educational programmes which should be structured to meet the patients' needs. Both case studies reported providing appropriate health education/promotion messages to the patients. In both the UK and Kuwait, nurses taught patients how to interpret laboratory results and spent time in consultation with patients, gathering baseline information about them, and providing relevant information about diabetes care. Patient empowerment and encouragement for self-management was an important aspect that nurses in both case studies included in diabetes care.

"We used to ask some patients to bring someone in their family or a friend who can speak both languages ...." (Nurse 13-Kuwait).

These findings indicate that nurses in both the UK and Kuwait adhere to the guidelines about the prescribed role of health education and health promotion.

\section{Providing Patient-Centred Care}

Patient centred care emerged as an important role in diabetes care. Patient-centred care approaches highlighted in the documents included providing patient follow-up care and keeping the patient informed about their own plan of care. It was noted that nurses involved in patient care were expected to provide the patient with support by creating and maintaining a good relationship with them, an approach that empowered patients to self-manage their condition. 
The care provided by nurses to diabetes patients was regarded as patient-centred as it aimed at addressing the holistic care needs of the patients. The nurses in both case studies provided various kinds of support to their patients to respond to their individual needs. Nurses reported attending to patients' diverse needs including cultural and financial issues, foot care, physical and psychological care, as well as social support.

"Our patients come with different needs and we make sure we cover these needs. Some of them [patients] have needs that are related to their cultural backgrounds, others have financial problems and in that case, we try to provide some solutions, though this needs other interventions that are not under our scope of practice ...." (Nurse 2-NUH)

Such care was regarded as holistic and patient focused and perceived to result into good patient outcomes.

\section{Promoting Self-Care}

Patient-centred care also entailed empowering patients to be able to manage their disease. Patient empowerment was emphasised in the guidelines, which highlighted the need for healthcare team members to uphold patients' rights to understand about managing their diabetes, and raise their awareness about the national associations from which they can seek further care. Nurses are required to involve the patients in planning and sharing plans of their treatment.

Patient empowerment and encouragement for selfmanagement was an important aspect that nurses in both case studies included in diabetes care. This included nurses educating the patients on how to monitor their health situations and how to administer certain medications for diabetes management.

Nurse demonstrated about blood sugar test and insulin... administration demonstrated how to use the pen and mixed insulin. (Observation 14-MoH).

\section{Prescribing Role}

Guidelines from the UK (such as those of the NDSAG) clearly elaborated on the prescribing role of nurses in diabetes care. Although nurses in both case studies reported being able to provide diabetes medication and adjust insulin, nurses in Kuwait cannot prescribe medication. By law, only doctors are mandated to prescribe in Kuwait, while In the UK, nurses are able to prescribe only after successfully completing a prescribing course:

“... protocol does not include insulin and I cannot prescribe it. I have to wait for my consultant for that patient before that decision has to be made.... This is one occasion yes where not everything is in the guidelines." (Nurse 8-UK).

\section{Multidisciplinary/Team Work}

An important approach identified in the national guidelines was teamwork. According to the standards in the national guidelines, a teamwork approach would minimise and control long-term diabetes complications, as it adds quality to the care provided. Nurses should collaborate with other nurses in different specialities or with other healthcare professionals.

In practice, nurses reported undertaking roles in collaboration with other nurses and other healthcare professionals. The roles undertaken on patients outside diabetes care made the diabetes nurse to act out of their scope of practice and were sometimes viewed as disruptive to the diabetes care role.

"When a nurse or a doctor at the ward called me up to teach a patient who is going to be discharged. A nurse in the ward can do the education. Doctors in the ward can do the discharge.... Those things might look small but they are interrupting our work." (Nurse 1-UK).

\section{Adapting Diabetes Care to Local Needs}

Guidelines suggested that nurses should follow some recommendations at the local level, such as local policies and individual clinical management plans that consider patients' conditions and circumstances. It was observed that diabetes care should be tailored to the local needs of patient and considerations should be made, putting considerations such as age, gender, religion, geographical setting of the patients.

Nurses reported providing diabetes care to patients in consideration of the above recommendations. In order to enhance patient-centred care, nurses paid attention to the individual considerations of patients.

\section{Discussion}

The guidelines on diabetes care that were reviewed in the current study included recommendations, policies and procedures that healthcare providers, including nurses, can follow when providing diabetes care. Burgers, et al. [25] claim that guidelines are sets of instructions that when applied improve patients' quality of care and therefore contribute to quality assurance of care. Glasgow, et al. [26] emphasise that the main role of quality assurance is to oversee the implementation of policies to enhance the health of people with long-term conditions, including diabetes. Hence, to ensure quality in the provision of care to diabetes patients, it is essential that nurses use available guidelines to direct their work. 


\section{Nurses' Attitudes towards Diabetes Care Guidelines}

Nurses in both case studies were found to be aware of how both international and local guidelines inform and give direction to their work. Some nurses felt that the guidelines could not fully address every patient's needs, as patients may differ in contexts. In Kuwait, nurses felt that guidelines provided limited coverage, resulting in them utilising their own knowledge and experience in providing diabetes care. On the other hand, the international guidelines were seen as being too general and included broad advice and recommendations without being explicit as to what should be accomplished by which team member working in diabetes care. This lack of specificity in the guidelines might result in nurses misunderstanding which recommendations pertain to them. Hence, although general guidelines are essential, it is important that specific instructions pertaining to nursing care is provided for proper direction of nursing care to diabetes patients.

The current study established that the available guidelines were generally broad, but reflected the need for nurses to tailor their applications to the local needs and contexts of their patients. Some authors recommend that treatment guidelines should be standardised internationally [25]. However, there are cultural and social variations between countries [27], which may motivate health professionals to establish individualised guidelines that can fit the specific needs of healthcare settings or patients' individual needs and contexts. As Inzucchi, et al. [28], recommend, treatment guidelines should be situated within the context of patients' requirements, preferences, and acceptance, an aspect that is respected in the reviewed guidelines and in current diabetes care practice.

\section{Nurses' Adherence to Diabetes Treatment Guidelines}

This research established that nurses applied diabetes care guidelines in different ways and degrees. The majority of nurses made use of the guidelines for various activities such as, providing advice about medication, education on lifestyle change, and self-care. Some authors have noted that healthcare professionals, including nurses, may not adhere either to their own roles or guidelines [29], a finding that differs from those of the current study, where it was reported that nurses adhered to almost all aspects that were described in the diabetes care guidelines. To increase the adherence of nurses to diabetes treatment/care guidelines, nurses require supportive environments, including the support from colleagues and management [22]. the application of diabetes care guidelines. Nurses recognised that guidelines may not be applicable in a similar manner, since patients may present with different needs. Hence patient factors were considered while providing diabetes care. By focusing at the patients, nurses provided patientcentred care, which is believed to enhance patient treatment outcomes [30]. Nurses also drew from their knowledge and diabetes care experience to implement care while taking into consideration the respective guidelines. Polit, et al. [31] suggest that healthcare providers' knowledge can be applied within the context of their practice and based on their knowledge, which is in line with what nurses reported in the current study. It is also recommended that regardless of the guidelines, nurses should tailor and implement interventions that are patient-centred [32,33]. These findings highlight the need for nurses to be flexible in applying diabetes care guidelines. In addition, the findings suggest the need for guidelines that are flexible and can be tailored to meet the particular patients' needs.

\section{Conclusions}

To our knowledge, document review of diabetes care/ treatment guidelines is under researched and therefore this study brings a new insight in the area of guidelines that are relevant to diabetes care/treatment. Our findings established that guidelines about diabetes care are essential in the provision of patient focused care, hence the need for their adoption in all healthcare settings. The findings showed that nurses utilise the guidelines to guide their work of nursing diabetes patients and while doing this, they take into consideration the individual needs of their patients. It is important that the guidelines provide specific roles for the different practitioners, and be flexible to adequately address the needs of the patients. Further research is essential to assess the application of international, national, and local guidelines and how their application influence diabetes care delivery.

\section{Strengths and Limitations}

Research in the area of implementation of diabetes care guidelines has majorly focused on examining the use of guidelines from the patients' perspectives. Our study is unique since it closely assesses the implementation of diabetes care guidelines from the perspectives of nurses. As a limitation, our article presents a general review of guidelines and how nurses did perform the roles described in these guidelines. These roles were assessed at a broader perspective. Hence it is important that a more specific assessment is done, through a quantitative study that will assess the estimates of adherence to the guidelines by the diabetes care nurses.

Contextual factors were an important consideration in 


\section{References}

1. ADA (2014a) Diabetes Basics American Diabetes Association. American Diabetes Association.

2. IDF (2013) IDF diabetes atlas. Brussels: International Diabetes Federation, International Diabetes Federation.

3. ADA (2009) Diabetes prevalence expected to double in next years American Diabetes Association, American Diabetes Association.

4. WHO (2014) Diabetes Mellitus, World Health Organisation.

5. Logue J, Walker JJ, Colhoun HM, Leese GP, Lindsay RS, et al. (2011) Do men develop type 2 diabetes at lower body mass indices than women? Diabetologia 54(12): 30033006.

6. Scobie IN, Samaras K (2014) Fast Facts: Diabetes Mellitus. Oxford: Health Press Limited.

7. CDCP (2011) National diabetes fact sheet: national estimates and general information on diabetes and prediabetes in the United States, Atlanta, GA: US Department of Health and Human Services, Centers for Disease Control and Prevention, 201(1).

8. WHO (2006) Definition and diagnosis of diabetes mellitus and intermediate hyperglycemia: report of a WHO/IDF consultation. Geneva: World Health Organisation, pp: $1-46$.

9. Diabetes UK (2013) Diabetes prevalence.

10. Dasman Diabetes Institute (2016) Diabetes Mellitus: Periodontal Disease and Mechanism of Inflammation.

11. Juul L, Maindal HT, Frydenberg M, Kristensen JK, Sandbaek A (2012) Quality of type 2 diabetes management in general practice is associated with involvement of general practice nurses. Prim care diabetes 6(3): 221228.

12. Chan MF, Zang YL (2007) Nurses' perceived and actual level of diabetes mellitus knowledge: results of a cluster analysis. J Clin Nurs 16(7B): 234-242.

13. Goodwin N, Curry N, Naylor C, Ross S, Duldig W (2010) Managing people with long-term conditions. An Inquiry into the Quality of General Practice in England. The King's Fund pp: 3-96.

14. Lu H, While AE, Barriball K (2008) Role perceptions and reported actual role content of hospital nurses in Mainland China. J Clin Nurs 17(8): 1011-1022.
15. Baldwin R, Duffield CM, Fry M, Roche M, Stasa H, et al. (2013) The role and functions of Clinical Nurse Consultants, an Australian advanced practice role: A descriptive exploratory cohort study. Int J Nurs Stud 50(3): 326-334.

16. Vrijhoef HJ, Diederiks JP, Spreeuwenberg C, Wolffenbuttel BH (2001) Substitution model with central role for nurse specialist is justified in the care for stable type 2 diabetic outpatients. J Adv Nurs 36(4): 546-555.

17. Denver EA, Barnard M, Woolfson RG, Earle KA (2003) Management of Uncontrolled Hypertension in a NurseLed Clinic Compared With Conventional Care for Patients with Type 2 Diabetes. Diabetes Care 26(8): 2256-2260.

18. Bloomer MJ, Cross WM (2011) An exploration of the role and scope of the clinical nurse consultant (CNC) in a metropolitan health service. Collegian 18(2): 61-69.

19. Onishi M, Kanda K (2010) Expected roles and utilization of specialist nurses in Japan: the nurse administrators' perspective. J Nurs Manag 18(3): 311-318.

20. Aalaa M, Malazy OT, Sanjari M, Peimani M, Mohajeri Tehrani M (2012) Nurses' role in diabetic foot prevention and care; a review. J Diabetes Metab Disord 11(1): 24.

21. Houweling ST, Kleefstra N, van Hateren KJ, Kooy A, Groenier KH, et al. (2009) Diabetes specialist nurse as main care provider for patients with type 2 diabetes. Neth J Med 67(7): 279-284.

22. Alshammari M, Adams A, Windle R, Bowskill D (2019) Nurses' perspectives about their role in diabetes care: a case study analysis.

23. ADA (2014b) Statistics about diabetes, American Diabetes Association.

24. Braun V, Clarke V (2013) Successful qualitative research: A practical guide for beginners Thousand Oaks: Sage publications.

25. Burgers JS, Bailey JV, Klazinga NS, Van Der Bij AK, Grol R, et al. (2002) Inside Guidelines Comparative analysis of recommendations and evidence in diabetes guidelines from 13 countries. Diabetes Care 25(11): 1933-1939.

26. Glasgow RE, Wagner EH, Kaplan RM, Vinicor F, Smith $\mathrm{L}$, et al. (1999) If diabetes is a public health problem, why not treat it as one? A population based approach to chronic illness. Annals of Behav Med 21(2): 159-170.

27. Green EG, Deschamps JC, Paez D (2005) Variation of individualism and collectivism within and between 20 countries: A typological analysis. Journal of cross- 
cultural psychology 36(3): 321-339.

28. Inzucchi SE, Bergenstal RM, Buse JB, Diamant M, Ferrannini E, et al. (2012) Management of hyperglycemia in type 2 diabetes: a patient-centered approach: position statement of the American Diabetes Association (ADA) and the European Association for the Study of Diabetes (EASD). Diabetes care 35(6): 1364-1379.

29. Grol R (2001) Successes and failures in the implementation of evidence-based guidelines for clinical practice. Medical care 39(8): II-46-II-54.

30. Ekman I, Swedberg K, Taft C, Lindseth A, Norberg A, et al.
(2011) Person-centered care-Ready for prime time. Eur J Cardiovasc Nurs 10(4): 248-251.

31. Polit DF, Beck CT (2008) Nursing research: Generating and assessing evidence for nursing practice. New York: Lippincott Williams \& Wilkins.

32. Harrison MB, Légaré F, Graham ID, Fervers B (2010) Adapting clinical practice guidelines to local context and assessing barriers to their use. CMAJ 182(2): E78-E84.

33. Ahmad MM, Alasad JA (2004) Predictors of patients' experiences of nursing care in medical-surgical wards. Int J Nurs Pract 10(5): 235-241. 